\title{
A utilização de Repositórios de Objetos de Aprendizagem na Educação Infantil
}

\author{
Bárbara Fernandes da Silva de Souza1, Apuena Vieira Gomes ${ }^{2}$ \\ ${ }^{1,2}$ Programa de Pós-graduação em Inovação em Tecnologias Educacionais (PPgITE) \\ do Instituto Metrópole Digital (IMD) \\ da Universidade Federal do Rio Grande do Norte (UFRN) \\ barbarafernandesacademicolgmail.com, apueneeimd.ufrn.br
}

\begin{abstract}
This article is a cut of an ongoing Master's dissertation and brings a survey of the existing Learning Object Repositories and analysis of those who have Digital Learning Objects geared towards Early Childhood Education. It is based on qualitative and quantitative approaches and uses as a methodology the bibliographic research, based on an exploratory analysis. Their considerations point to Learning Object Repositories as an auxiliary tool that can aid in the planning, inclusion and execution of activities involving information and communication technologies as well as in their continuing education.
\end{abstract}

Resumo. Este artigo é um recorte de uma dissertação de mestrado em andamento e traz um levantamento dos Repositórios de Objetos de Aprendizagem existentes e análise dos que possuem Objetos de Aprendizagem voltados para a Educação Infantil. Tem como base uma abordagem quali-quanti e utiliza como metodologia a pesquisa bibliográfica, a partir de uma análise exploratória. Suas considerações apontam que os Repositórios de Objetos de Aprendizagem são uma ferramenta que podem auxiliar o professor no planejamento, na inclusão e execução de atividades que envolvam as TDIC assim como na sua formação continuada.

\section{Introdução}

Nos 23 anos de vigor da Lei de Diretriz e Bases da Educação Nacional (Lei: 9394/96) alguns dos aspectos do artigo 29 ganharam novos contornos. As relações sociais estão em constante transformação e os aspectos relacionados à tecnologia e à interação digital são cada vez mais frequentes na Geração Alpha que, de acordo com Indalécio e Ribeiro (2017), é composta por crianças nascidas após 2010.

O uso cada vez mais frequente de ferramentas tecnológicas por parte dos educandos impõe aos profissionais da educação um olhar "inovador e inclusivo a questões centrais do processo educativo: o que aprender, para que aprender, como ensinar, como promover redes de aprendizagem colaborativa e como avaliar o aprendizado". (BRASIL, 2017. p. 14).

Vídeos, jogos e animações são alguns exemplos de recursos das Tecnologias Digitais da Informação e Comunicação (TDIC) que fazem parte do cotidiano infantil, dentro e fora das escolas, e podem ser classificados como Objetos de Aprendizagem (OA) pois, de acordo com Machado e Silva (2005), atuam como recurso didático auxiliando no processo de aprendizagem.

Sá Filho e Machado (2003) definem OA como recursos digitais que têm como característica a reutilização e a possibilidade de combinação com outros objetos. Desse 
VIII Congresso Brasileiro de Informática na Educação (CBIE 2019)

Anais do XXV Workshop de Informática na Escola (WIE 2019)

modo, pode ser gerado um ambiente de aprendizagem rico e flexível e ainda, segundo os autores, esses recursos podem ser arquivados em banco de dados, sendo conhecidos como repositórios, permitindo, assim, uma recuperação mais fácil e mais precisa durante a busca do OA.

Os Repositórios de Objetos de Aprendizagem (ROAs) são classificados em institucionais ou temáticos, sendo o primeiro relacionado às produções científicas de uma determinada instituição e o segundo destinado a áreas específicas da produção científica (BRASIL. 2018). Ambos são fontes de dados nos quais visam otimizar a busca de OAs, auxiliando o professor no planejamento e na utilização desses recursos.

Para Ieiri e Braga, os ROAs podem "ser definido como uma biblioteca digital onde se inserem, removem, disponibilizam, catalogam e armazenam recursos educacionais."(2015. p.733). O controle das atividades realizadas no interior dos ROAs pode ser executado, segundo Bonetti e Wangenheim (2013), através das funcionalidades de gerenciamento de acesso (cadastro de usuários) e de dados (edição e remoção de $\mathrm{OA}$ ), permitindo que os membros cadastrados, que fazem parte da comunidade do repositório, possam compartilhar com maior facilidade e eficiência os OAs.

O presente estudo tem como objetivo realizar o levantamento do estado da arte dos Repositórios Objetos de Aprendizagem (ROA) no qual possa auxiliar os professores da Educação Infantil na busca, seleção e inclusão dos OA em seus planejamentos, e possibilitando, assim, o uso das TDICs no currículo da Educação Infantil de acordo com os campos de experiências da BNCC.

\section{Metodologia}

A metodologia utilizada teve como base uma abordagem quali-quanti e um estudo exploratório a partir de uma pesquisa bibliográfica que "se realiza a partir do registro disponível, decorrente de pesquisa anteriores [...] Utiliza-se de dados ou de categorias teóricas já trabalhados por outros pesquisadores e devidamente registrados". (SEVERIANO, 2007, p. 122).

A pesquisa foi realizada em duas fases: a primeira foi composta pelo levantamento dos Repositórios Digitais $(\mathrm{RD})$ e a segunda, pela análise dos repositórios destinados a Educação Infantil.

\subsection{Levantamento dos Repositórios Digitais (RD)}

O levantamento partiu do uso dos descritores: Repositório de Objetos de Aprendizagem e Repositório Digital na base de busca Google. Foram encontrados 6 repositórios/referatórios, pesquisas (artigos, dissertações e teses), matérias informativas (revistas on-lines) e três listas que serviram de base para consulta, sendo elas: Objetos de Aprendizagem Referatório ${ }^{1}$; Metodologia para o Desenvolvimento de Objetos de Aprendizagem $^{2}$ e por último, a Lista de repositórios de recursos educacionais disponíveis online ${ }^{3}$. Essas três listas totalizaram 102 referências de repositórios, porém excluindo os itens repetidos e os links sem acesso, restaram 37 que, junto aos 6 iniciais, totalizaram 43 repositórios.

\footnotetext{
${ }^{1}$ Fonte: https://repositoriodeobjetosdeaprendizagem.blogspot.com/2011/05/repositorios-nacionais.html

${ }^{2}$ Fonte: http://proec.ufabc.edu.br/uab/index.php/repositorio-metoa2-1

${ }^{3}$ Fonte:https://pt.wikiversity.org/wiki/Lista_de reposit\%C3\%B3rios_de recursos educacionais_dispon $\%$ C3 \%ADveis online\#Acervo de Recursos_Educacionais em_Sa\%C3\%BAde_ARES)
} 
VIII Congresso Brasileiro de Informática na Educação (CBIE 2019)

Anais do XXV Workshop de Informática na Escola (WIE 2019)

Essa primeira busca demonstrou resultados com iniciativas de diversas partes do país. Em comum, os repositórios visitados têm como missão disponibilizar conteúdo digital de qualidade para melhoria da prática pedagógica e difusão do conhecimento em todos os Níveis e Modalidades de Ensino.

\subsection{Análise dos repositórios destinados a Educação Infantil}

Para esta segunda fase do estudo, foram selecionados 9 repositórios para análise. Estabeleceu-se como critério de escolha o fato de serem criados e mantidos, prioritariamente, por órgãos públicos com acesso gratuito, com links ativos e que tenham a Educação Infantil como um dos eixos de atuação; no qual se buscou extrair as respostas para as seguintes questões: Q1: Quem é o responsável pela criação e manutenção do RD? Q2: Qual o público alvo? Q3: Qual o nível de ensino / disciplina que os ROAs se dispõem a atender? Q4: Quantos Objetos de Aprendizagens destinados a Educação Infantil o RD possui? Q5: Quantidades e tipos dos OAs que aparecem com maior frequência? Q6: Os OAs referenciam os campos de experiências da BNCC?

Educopédia - Q1: Prefeitura do Rio de Janeiro - Secretaria Municipal de Educação. Q2: Profissionais da Educação, pais e alunos da rede de ensino. Q3: Educação Infantil, Ensino Fundamental, EJA, Educação Especial e Formação para os Professores. Q4 e Q5: Não foi possível quantificar os OAs. Q6: Devido à data de postagem dos OAs, nenhum apresentou indicação dos campos de experiências da BNCC.

Escola Digital - Q1: Instituto Natura, Fundação Telefônica VIVO, Instituto Inspirare, Fundação Lemann e Fundação Vanzolini em parceria com Estados e Municípios. Q2: Profissionais da Educação, pais e alunos. Q3: Educação Básica, Educação do Campo, Educação Indígena, Educação Especial, EJA, Educação Profissional e Educação Quilombola. Q4: 1087 . Q5: 605 videos; 219 animações e 42 livro game. Q6: Grande parte classificada de acordo com os campos de experiências trazidos pela BNCC, porém nem todos os objetivos de aprendizagem e desenvolvimento são da Educação Infantil, mas sim dos anos iniciais do Ensino Fundamental.

Escolas na Rede - Q1: Governo do Estado do Rio Grande do Norte em parceria com a Rede Escola Digital. Q2: Profissionais da Educação e alunos da rede pública do Estado do Rio Grande do Norte. Q3: Educação Infantil, Ensino Fundamental, Educação especial e EJA. Q4: 8685. Q5: 455 são vídeos; 212 animações e 39 jogos educativos. Q6: Grande parte dos recursos estão categorizados de acordo com os campos de experiências da BNCC.

Objeto de Aprendizagem para Matemática - OBAMA - Q1: Universidade Federal do Rio Grande do Norte - UFRN. Q2: Professores. Q3: Educação Básica. Disciplinas: Matemática. Q4: $28^{6}$. Q5: 28 jogos. Q6: A busca feita com os mecanismos de seleção no nível de ensino Educação Infantil e BNCC não obtiveram resultado, mesmo utilizando a opção oferecida pela plataforma: Parâmetros Curriculares Nacionais - PCN, foram remetidos 28 jogos. Os OAs classificados estavam com indicação dos

\footnotetext{
${ }^{4}$ Busca realizada em 13 de junho de 2019.

${ }^{5}$ Busca realizada em 17 de junho de 2019.

${ }^{6}$ Busca realizada em 05 de junho de 2019.
} 
VIII Congresso Brasileiro de Informática na Educação (CBIE 2019)

Anais do XXV Workshop de Informática na Escola (WIE 2019)

objetivos de aprendizagem e desenvolvimento do Ensino Fundamental.

Plataforma Anísio Teixeira - Q1: Governo do Estado da Bahia - Secretaria de Educação. Q2: Profissionais da Educação e alunos da rede pública do Estado da Bahia. Q3: Educação Básica. Q4: 717 . Q5: 32 vídeos; 15 documentos /experimento (plano de aula) e 13 indicações de sites. Q6: Os OAs observados não apresentavam referências aos campos de experiências da BNCC, a plataforma apresenta o conteúdo programático e os objetivos dos OAs.

Plataforma MEC de Recursos Educacionais Digitais (MEC RED) - Q1: Brasil Ministério da Educação. Q2: Plataforma colaborativa destinado a profissionais de educação e alunos. Q3: Educação Básica. Q4: $909^{8}$. Q5: 375 Experimento Prático; 192 Software Educacional e 111 Vídeos. Q6: Todos os recursos observados durante a análise da plataforma apresentavam uma descrição contendo informações sobre os recursos e seus objetivos, sem menção às habilidades da BNCC.

Portal Dia a Dia da Educacão - Q1: Governo do Estado do Paraná - Secretaria de Educação. Q2: Profissionais de educação e alunos da rede pública do Estado do Paraná. Q3: Educação Básica. Q4: 8909. Q5: 602 vídeos; 101 Páginas Webs e 77 Recursos Textuais. Q6: Como observado no repositório Rede Digital, nem todos os OAs estavam categorizados pelas habilidades propostas pela BNCC para a Educação Infantil.

Portal do Professor - Q1: Brasil - Ministério da Educação, Ministério da Ciência e Tecnologia. Q2: Professores. Q3: Educação Básica. Q4: 869 ${ }^{10}$. Q5: 405 Experimentos práticos; 198 Software Educacionais e 107 Áudios. Q6: Os recursos são apresentados com objetivo e indicação de uso, mas devido à data de postagem dos mesmos, nenhum apresentou indicação dos campos de experiências da BNCC.

TV Escola - O Canal da Educação - Q1: Brasil - Ministério da Educação. Q2: Professores e Alunos. Q3: Educação Básica. Q4 e Q5: Não foi possível quantificar os OAs. Q6: Não se aplica. Para a educação infantil, a plataforma disponibiliza vídeos com conteúdo formativo e com conteúdo informativo para professores e animações para o uso em sala de aula.

\section{Considerações}

Um dos grandes desafios dos profissionais de Educação Infantil é integrar as TDICs as suas práticas, sincronizando os campos de experiências listados pela BNCC ao repertório de mundo digital que a Geração Alpha traz consigo e o seu próprio conhecimento e domínio das ferramentas tecnologias. Os Repositórios de Objetos de Aprendizagem apresentam-se como um instrumento facilitador, auxiliando a busca, a seleção de recursos digitais e plano de aulas para uso na prática didática.

Os repositórios selecionados para a segunda fase de análise deste trabalho demonstraram recursos que, facilmente, podem ser incorporados ao planejamento docente, permitindo não só o uso dos OAs por crianças de 4 a 5 anos em 11 meses,

\footnotetext{
${ }^{7}$ Busca realizada em 17 de junho de 2019.

${ }^{8}$ Busca realizada em 05 de junho de 2019.

${ }^{9}$ Busca realizada em 17 de junho de 2019.

${ }^{10}$ Busca realizada em 05 de junho de 2019.
} 
como a formação continuada e a capacitação docente. Todos os repositórios estudados são gratuitos e possuem, além de recursos on-line, a possibilidade de download, o que facilita o uso, já que o acesso à internet ainda não é uma realidade em todas as escolas, principalmente nas da rede pública.

Introduzir nas escolas de Educação Infantil um planejamento que contemple o uso da tecnologia é um ato que vai além do domínio em que o professor possa ter sobre o uso das ferramentas tecnológicas e que perpassa pela estrutura física de cada instituição, pela formação inicial e continuada dos professores e pelo currículo proposto pelas unidade escolares.

Alguns dos repositórios já possuem a categorização de seus OAs de acordo com a BNCC, o que torna o seu uso ainda mais significativo e fundamentado. Este não é apenas o uso do recurso pelo recurso, é uma prática de inclusão da e para a tecnologia, considerando o perfil dos alunos que, cada vez mais cedo, têm acesso a recursos digitais.

Esse artigo é um recorte de um estudo maior, ligado à dissertação de um projeto de mestrado em andamento que tem, como ponta de partida, a estruturação de referenciais de uso dos Objetos de Aprendizagem no planejamento do professor da Educação Infantil.

\section{Referências}

Bonetti, Thiago M.; Wangenheim, Christiane G. V. (2013).Desenvolvimento de um Repositório de Jogos Educacionais para o Ensino de Gerenciamento de Projetos. In: $2^{\circ}$ Congresso Brasileiro de Informática na Educação (CBIE) $24^{\circ}$ Simpósio Brasileiro de Informática na Educação (SBIE).

Brasil. Lei No 9.394, de 20 de dezembro de 1996. Estabelece as Diretrizes e Bases da Educação Nacional. Brasília: Ministério da Educação, 1996.

Brasil. Base Nacional Comum Curricular - BNCC. Ministério da Educação. (2017). Disponivel em: http://basenacionalcomum.mec.gov.br/. Acesso em 26 de jun. 2019.

Ieiri, A. e Braga, J. Problemas de Usabilidade em Repositórios de Objetos de Aprendizagem a partir de Estudos Primários (2015). In: Anais do $26^{\circ}$ Simpósio Brasileiro de Informática na Educação (SBIE), Disponivel em: http://www.br-ie.org/pub/index.php/sbie/article/view/5350/3713. Acesso em 16 de jul de 2019

Indalécio, Anderson B.; Ribeiro, Maria da Graça M. (2017). Gerações Ze Alfa: os novos desafios para a educação contemporânea. Revista UNIFEV: Ciência \& Tecnologia 2. Disponivel em: http://periodicos.unifev.edu.br/index.php/RevistaUnif ev/article/view/234 Acesso em 25 de maio de 2019.

Machado, Lisandro L.; Silva, Juliano T. (2005). Objeto de aprendizagem digital para auxiliar o processo de ensino-aprendizagem no Ensino Técnico em Informática. Novas Tecnologias na Educação, CINTED-UFRGS v $3 \mathrm{n}^{\circ} 2$, Novembro. Disponivel em: https://www.seer.ufrgs.br/renote/article/view/13953/78 52. Acesso em 08 de jul de 2019.

Sá Filho, Clovis S.; Machado, Elian de Castro. (2003) O computador como agente transformador da educação e o papel do objeto de aprendizagem. Disponivel em: http://www.abed.org.br/seminario2003/texto11.htm Acesso em 08 de jul de 2019.

Severiano, Antônio J. (2007). Metodologia do trabalho científico. $23^{\circ}$ ed. rev. e atual. São Paulo: Cortez. 